\title{
A FORMAÇÃO DOS PROFESSORES NA EDUCAÇÃO INFANTIL NA PERSPECTIVA DO BRINCAR
}

\author{
${ }^{1}$ Evanileide Patrícia Lima Figueira, ${ }^{2}$ Lívia Bernardes Rodrigues, ${ }^{3}$ Renata Portela Rinaldi \\ ${ }^{1}$ Mestranda do Programa de Pós-Graduação em Educação da Universidade Estadual Paulista - UNESP, Campus \\ Presidente Prudente, SP. E-mail: evanileidelima@gmail.com \\ ${ }^{2}$ Mestranda do Programa de Pós-Graduação em Educação da Universidade Estadual Paulista - UNESP, Campus \\ Presidente Prudente, SP. \\ ${ }^{3}$ Doutora em Educação pela Universidade Federal de São Carlos - UFSCar. Professora do Departamento de Educação e \\ do Programa de Pós-Graduação em Educação da Universidade Estadual Paulista - UNESP, Campus Presidente \\ Prudente, SP. E-mail: renata.rinaldi@fct.unesp.br
}

\section{RESUMO}

A Educação Infantil, primeira etapa da educação básica, possui peculiaridades próprias, decorrente das especificidades das crianças, que tem o brincar como atividade fundamental ao seu desenvolvimento. Nessa perspectiva, temos como objetivo compreender o que revelam as produções científicas em teses e dissertações acerca da formação de professores na Educação Infantil, tendo o Brincar como eixo norteador do processo. A pesquisa teórica vincula-se a uma pesquisa mais ampla sobre a formação de professores e o trabalho docente nos diferentes níveis de ensino. Foi norteada pela abordagem qualitativa, do tipo pesquisa bibliográfica; realizada na base de Dados da Biblioteca Digital de Teses e Dissertações (BDTD), no período de 2000-2016, com critérios previamente definidos. Inicialmente os resultados apontaram 50 trabalhos, que, após análise individual, constatou-se apenas 3 vinculados à temática sobre o Brincar. Percebemos, de modo geral, que a etapa da Educação Infantil parece silenciada nas pesquisas realizadas nos últimos 17 anos.

Palavras-chave: Formação de Professores. Trabalho docente. Educação infantil. Brincar. Pesquisa bibliográfica.

\section{TEACHER TRAINING IN EARLY CHILDHOOD EDUCATION IN THE PLAYING PERSPECTIVE}

\begin{abstract}
Early Childhood Education, the first stage of basic education, has its own peculiarities, arising from children specific characteristics, among them there is the action of playing, which is an essencial activity for children development. From this perspective, we aim to understand what scientific production in theses and dissertations reveal on the theme of teacher training in Early Childhood Education having the action of playing as the main guide of the process. The theoretical research is linked to a broader research on teacher training and teacher's work at different levels of education. The qualitative approach was used, classified as a bibliographic research; it made use of the database of the Digital Library of Theses and Dissertations (BDTD), from the period of 2000 to 2016, with previously defined criteria. Initially the results pointed out 50 studies which after individual analysis, only 3 were related to the Playing theme. Generally, it was perceived that the stage of Early Childhood Education seems to silenced in the research carried out in the last 17 years.
\end{abstract}

Keywords: Teacher Training. Teacher's work. Early Childhood Education. Playing. Bibliographic research.

\section{INTRODUÇÃO}

A educação ao se configurar como um direito de todos (BRASIL, 1988) e dever do estado, à ocorrer nas escolas, sob a responsabilidade do professor, incita desde então uma mobilização social e política, pela garantia do acesso à educação. Dessa forma, novas demandas e necessidades emergem ao longo do tempo, especialmente após a publicação da Lei de Diretrizes e Bases (LDB) no 9.394 (BRASIL, 
1996), entre as quais a ampliação de escolas e investimentos na formação de professores que supram as necessidades advindas da intensificação da oferta de ensino (SAVIANI, 2009), especialmente no que diz respeito à Educação Infantil.

Nesse cenário, os professores assumem o status de profissionais, e a ação política é atribuída ao seu papel, já que se tornam instrumento possibilitador de ascensão social (NÓVOA, 1999, p. 17). Tal concepção promove assim uma vinculação do trabalho docente à formação humana, com vistas a dar condições aos sujeitos ao pleno exercício da cidadania. 0 estabelecimento de tal relação promove na trajetória histórica da formação de professores, influências decorrentes das mudanças e aspirações sociais de cada época, resultantes dos novos desafios educacionais propostos (CUNHA, 2013).

No que se refere à Educação Infantil, esta ao adquirir o seu caráter pedagógico, configurando-se como primeira etapa da Educação Básica (BRASIL, 1996), assume a responsabilidade e intencionalidade educativa sobre o desenvolvimento e aprendizagem das crianças pequenas, tornando-se um desafio à garantia do acesso e qualidade da educação nessa etapa de ensino, que perpassa desde a infraestrutura à formação de qualidade dos educadores que nela atuam.

Tendo em vista a garantia de um ensino que atendesse as necessidades e especificidades das crianças, foram estabelecidas ao longo do tempo, diversas iniciativas políticas que dispõem sobre a formação específica dos profissionais dessa etapa de ensino (BRASIL, 1996) a orientação sobre os objetivos, conteúdos e práticas educativas no interior das instituições (BRASIL, 1998), o currículo e proposta pedagógica que devem compô-la (BRASIL, 2009) dentre outros que tem como objetivo zelar pelo direito das crianças a um ensino de qualidade.

O ensino na Educação Infantil assume suas especificidades, em favor ao modo particular das crianças se desenvolverem, distanciando-se das demais etapas de ensino, dadas as singularidades que coincidem com as necessidades e interesses das crianças, sendo o brincar um dos princípios norteadores desse processo.

Reconhecida a necessidade lúdica $\mathrm{e}$ interativa da criança perceber o mundo e a si mesmo, na construção de seu conhecimento as
Diretrizes Curriculares Nacionais para Educação Infantil (BRASIL, 2009, p. 25) define como eixo norteador do currículo as brincadeiras e interações, estabelecendo uma proposta de educação que supera o caráter assistencialista historicamente concebido às creches e préescolas, fortalecendo a indissociação entre o cuidar e educar e o caráter pedagógico destas instituições.

Sobre tais necessidades específicas, é possível identificar uma ampla realização de estudos sobre o desenvolvimento infantil e a educação das crianças pequenas que buscam contemplar a forma peculiar dela se desenvolver, em seus diferentes aspectos, e que servem de subsídios à organização do trabalho a ser desenvolvido com e para elas (VYGOTSKY, 1995; PIAGET, 1994; OLIVEIRA, 2002).

O brincar ou a brincadeira [...] é a atividade principal da criança. Sua importância reside no fato de ser uma ação livre, iniciada e conduzida pela criança com a finalidade de tomar decisões, expressar sentimentos e valores, conhecer a si mesma, as outras pessoas e o mundo em que vive. Brincar é repetir ações prazerosas, expressar situações imaginárias, criativas, compartilhar brincadeiras com outras pessoas, expressar sua individualidade e sua identidade, explorar a natureza, os objetos, comunicar-se e participar da cultura lúdica para compreender seu universo. Ainda que o brincar possa ser considerado um ato inerente à criança, exige um conhecimento, um repertório que ela precisa aprender. 
(BRASIL, 2012, p.10) (grifo nosso).

Portanto, o brincar é uma aprendizagem social (OLIVEIRA, 2012, p. 202) sendo uma atividade onde a criatividade se apresenta, tornando-se um mecanismo psicológico favorável ao distanciamento do real (BROUGÉRE, 2002, p. 19), essencial ao desenvolvimento da imaginação, permitindo à criança a busca pela compreensão do mundo à sua volta de forma lúdica.

No entanto, apesar de serem vários os elementos que podem contribuir ou não para a qualidade do ensino, tais como valorização social da profissão, condições de trabalho, infraestrutura da escola (GATTI; BARRETO; ANDRÉ, 2011), a formação docente se apresenta como um dos fatores determinantes para a consolidação de práticas educativas de qualidade (BARRETO, 1998; KISHIMOTO, 2002).

Partindo desse pressuposto, o presente trabalho tem como objetivo compreender o que revelam as produções científicas em teses e dissertações acerca da formação de professores na Educação Infantil, tendo o Brincar como eixo norteador do processo.

\section{METODOLOGIA}

A pesquisa teórica, qualitativa de natureza descritiva e exploratória, segundo Deslauriers e Kérisit (2010, p. 130) “[...] poderá servir para determinar impasses e os bloqueios, capazes de entravar um projeto de pesquisa em grande escala. [...] Ela é, a maior parte do tempo, completa em si mesma, e não tem obrigatoriamente necessidade de ser continuada por outros pesquisadores, por meio de outras técnicas".

Em nosso caso, por vincular-se à pesquisa mais ampla, o processo de coleta de dados foi rigorosamente planejado a partir de critérios previamente definidos e orientadores para o levantamento bibliográfico nas diversas bases de dados. Para o presente texto, apresentaremos os resultados parciais derivados de teses e dissertações na Base de Dados BDTD, no período de 2000 a 2016.

A busca pela compreensão da temática através das pesquisas realizadas sobre a mesma justifica-se pelo fato de que "[...] a pesquisa acompanha os movimentos político-econômicos e socioculturais que dão forma ao desempenho docente, quer no plano real, quer no ideal" (CUNHA, 2013, p. 611), fornecendo assim evidência que denotam a presença ou ausência de temas essenciais às mudanças almejadas para a educação.

Sendo assim, a metodologia adotada tem sua relevância, pois a partir de uma busca aprofundada nos estudos realizados em torno da temática ou etapa de ensino, surge a possibilidade de "[...] mapear a área, traçar um panorama das principais tendências teóricasmetodológicas de investigação, discutir resultados e apontar tanto avanços e conquistas quanto as (muitas) lacunas ainda existentes" (KRAMER, 1996, p. 27).

Dessa forma, foram utilizados os seguintes descritores: Formação de Professores, Formação de Professores and Educação Infantil, Trabalho Docente, Trabalho Docente and Educação Infantil. Para a pesquisa com cada descritor foi aplicado os filtros da Base de Dados, a saber: Assunto (de acordo com os descritores); Idioma, selecionando o Português, e o Ano da publicação, inserindo neste campo o período de 2000 a 2016, que é o foco da pesquisa. Tal refinamento foi aplicado, com o objetivo de delimitar a busca, concentrando os resultados sobre a temática em pauta.

Os resultados para cada descritor foram analisados a partir do acesso ao trabalho completo, e considerados somente os que correspondiam à temática investigada. A necessidade e critério em acessar o trabalho na íntegra se deu pelo fato de muitos títulos não evidenciarem o assunto abordado na pesquisa, podendo este ficar oculto no título, mas comparecer nas palavras-chave ou resumo.

Posteriormente, foi feito o fichamento de cada trabalho a partir de um protocolo organizado pela coordenadora da pesquisa e a partir destes foram estabelecidos alguns indicadores quanto à formação (inicial, continuada, inicial e continuada) e trabalho docente. Para esse texto, faremos a exposição dos resultados considerando o objeto investigado e que em seu escopo trouxeram discussões sobre o Brincar em suas diferentes interfaces.

\section{RESULTADOS}

São apresentados os dados quantitativos, estabelecendo relações descritivas entre eles. Em uma primeira consulta com os descritores obtivemos os seguintes resultados por ano, expressos no Quadro 1, em que é possível verificar um número reduzido de pesquisas sobre a temática nessa etapa de ensino. 
Quadro 1.Resultados da pesquisa de levantamento bibliográfico na BDTD no período de 2000-2016

\begin{tabular}{|c|c|c|c|}
\hline Ano & $\begin{array}{c}\text { Total de Teses } \\
\text { e dissertações }\end{array}$ & $\begin{array}{c}\text { Teses e dissertações } \\
\text { selecionadas } \\
\text { Frequência Absoluta }\end{array}$ & $\begin{array}{c}\text { Teses e dissertações } \\
\text { selecionadas } \\
\text { Frequência Relativa } \\
\text { (\%) }\end{array}$ \\
\hline 2000 & 5.267 & 0 & 0,0 \\
\hline 2001 & 7.647 & 0 & 0,0 \\
\hline 2002 & 9.275 & 0 & 0,0 \\
\hline 2003 & 11.845 & 0 & 0,0 \\
\hline 2004 & 12.976 & 1 & 2 \\
\hline 2005 & 17.413 & 1 & 2 \\
\hline 2006 & 24.664 & 3 & 6 \\
\hline 2007 & 27.434 & 5 & 10 \\
\hline 2008 & 30.121 & 1 & 2 \\
\hline 2009 & 32.433 & 4 & 8 \\
\hline 2010 & 35.386 & 3 & 6 \\
\hline 2011 & 35.951 & 2 & 4 \\
\hline 2012 & 40.406 & 5 & 10 \\
\hline 2013 & 45.659 & 5 & 22 \\
\hline 2014 & 47.300 & 11 & 12 \\
\hline 2015 & 41.433 & 6 & 6 \\
\hline 2016 & 30.657 & 3 & 100 \\
\hline Total & 455.867 & 50 & \\
\hline
\end{tabular}

Fonte: Sistematizado pelas autoras a partir processamento dos dados na etapa 2.

Os resultados também podem ser observados, no Quadro 2, a partir da pesquisa realizada por descritor.

Quadro 2. Distribuição das produções pesquisadas por descritor.

\begin{tabular}{|l|c|c|}
\hline \multicolumn{1}{|c|}{ Descritores } & $\begin{array}{c}\text { Total de Teses e } \\
\text { Dissertações }\end{array}$ & $\begin{array}{c}\text { Total de Teses e } \\
\text { Dissertações selecionadas }\end{array}$ \\
\hline Formação de Professores & 1229 & 31 \\
\hline $\begin{array}{l}\text { Formação de Professores and Educação } \\
\text { Infantil }\end{array}$ & 40 & 03 \\
\hline Trabalho Docente & 213 & 16 \\
\hline Trabalho Docente and Educação infantil & 13 & 0 \\
\hline Total & $\mathbf{1 4 9 5}$ & $\mathbf{5 0}$ \\
\hline
\end{tabular}

Fonte: Sistematizado pelas autoras a partir dos resultados obtidos na BDTD.

Os resultados de uma segunda etapa de processamento dos dados, com enfoque no Brincar como eixo norteador do processo da Formação dos professores na Educação Infantil nos revelou apenas 4 trabalhos que trouxeram para discussões a referida temática (Quadro 3). 
Quadro 3. Distribuição das teses e dissertações selecionadas para análise.

\begin{tabular}{|l|c|l|c|c|}
\hline Ano & $\begin{array}{c}\text { Tipo de } \\
\text { trabalho }\end{array}$ & \multicolumn{1}{|c|}{ Título } & Autor & $\begin{array}{c}\text { Filiação } \\
\text { Institucional do } \\
\text { autor }\end{array}$ \\
\hline 2004 & Dissertação & $\begin{array}{l}\text { O Brincar e suas várias linguagens: um } \\
\text { estudo de caso enfocando a Formação } \\
\text { do professor de Educação Infantil }\end{array}$ & $\begin{array}{c}\text { Sueli Teresinha } \\
\text { Pasqualini }\end{array}$ & UDESC \\
\hline 2013 & Dissertação & $\begin{array}{l}\text { Formar e Formar-se: Políticas e } \\
\text { Práticas }\end{array}$ & Thaís Oliveira de Souza & UFPB \\
\hline 2014 & Dissertação & $\begin{array}{l}\text { A função do professor com crianças } \\
\text { pequenas: impasses frente ao enigma } \\
\text { infantil no contexto escolar }\end{array}$ & Cristina Rocha Dias & USP \\
\hline & Dissertação & $\begin{array}{l}\text { O parque como espaço educativo: } \\
\text { práticas corporais num projeto de } \\
\text { formação de professoras para } \\
\text { educação infantil }\end{array}$ & Natália Tarinazzo \\
Figueira & USP \\
\hline
\end{tabular}

Fonte: Sistematizado pelas autoras.

\section{DISCUSSÃO}

Os achados expostos nos quadros 1, 2 e 3 , respectivamente, permitem afirmar que 0 interesse pela temática da formação de professores na etapa da Educação Infantil não foi significativo, apesar haver um aumento das pesquisas a partir do ano de 2014. Esse resultado revela um silenciamento do tema pelos programas de pós-graduação nos últimos 16 anos. Quando incorporamos o brincar nesse processo, os resultados são ainda mais drásticos, pois dos quatro trabalhos identificados, apenas dois trazem o brincar como eixo central da pesquisa, (PASQUALINI, 2004; FIGUEIRA, 2014), sendo tratado nos demais (SOUZA, 2013; DIAS, 2014) de forma transversal, porém, ambos destacando a importância do mesmo para o desenvolvimento infantil.

A invisibilidade das pesquisas em torno do Brincar na Formação dos Professores denota que apesar de haver um crescente interesse em investigar o professor (ANDRÉ, 2010) , essa busca se concentra ainda em "[...] compreender como se constituem os saberes dos professores, investigar sua história pessoal e profissional, as coerções que sofrem [...] as características da sua posição na instituição educacional"(OLIVEIRA, 2011, p.21), mantendo ainda silenciados alguns temas tão importantes para esse campo de estudo e em especial para essa etapa de ensino.

\section{CONCLUSÃO}

Propusemos, neste texto, compreender o que revelam as produções científicas em teses e dissertações acerca da formação de professores na Educação Infantil, tendo o Brincar como eixo norteador do processo.

Com os resultados obtidos foi possível concluir que nas pesquisas realizadas ao longo dos 16 anos poucas discussões e reflexões teóricas e práticas foram realizadas. Sem a pretensão de esgotar a temática, mas com intuito de contribuir para o campo, esses achados nos permitem fazer alguns apontamentos:

- Em relação à quantidade reduzida de pesquisas em torno da temática na Formação de professores, especificamente na Educação Infantil, destacamos como necessário que essa abordagem seja mais investigada, pois dada a importância que essa etapa de ensino representa na vida das crianças e em seu desenvolvimento, e o papel do professor na efetivação do ensino que nela é oferecido, consideramos de extrema importância os indicativos que as pesquisas podem trazer à tona, de forma a contribuir para a identificação de aspectos que afetam diretamente a qualidade do ensino, assim como mudanças e transformações necessárias para o sucesso da criança nas etapas subsequentes de seu processo de escolarização.

- No que se refere ao Brincar no processo de Formação dos Professores, a quantidade de estudos identificados é ainda menor, denotando a emergência em colocá-la como foco das pesquisas, já que 0 brincar pode assumir diferentes concepções, nem sempre condizentes com as necessidades e especificidades das crianças, devendo então, a nosso ver, e sem pretensão de conclusão, fazer parte da agenda de formação dos professores, para que assim, a partir da compreensão sobre o mesmo, estes 
tenham condições efetivas de garantir às crianças a presença do mesmo nas práticas educativas a elas designadas.

Os dados permitiram observar que a questão do brincar não pode ser desvinculada da reflexão sobre a formação profissional do professor da Educação Infantil, seja na formação inicial ou continuada. Por fim, ressaltamos o papel e a responsabilidade social da universidade que deve estar atenta aos indicadores e necessidades do campo nos diferentes momentos históricos tanto no que tange à formação de professores quanto à produção de conhecimento científico, especialmente a partir dos programas de pós-graduação.

\section{REFERÊNCIAS}

ANDRÉ, M. Formação de professores: a constituição de um campo de estudos. Educação, Porto Alegre, v. 33, n. 3, p. 174-181, set./dez. 2010. Disponível em: http://revistaseletronicas.pucrs.br/ojs/index.php /faced/article/view/8075/5719. Acesso em: 02 fev. 2017.

BARRETO, A. M. R. Situação atual da educação infantil no Brasil. In: BRASIL. Ministerio da Educação e do desporto. Subsídios para o credenciamento e funcionamento de instituições de educação infantil. Brasília: MEC/SEF/COEDI, 1998. v. 2

BROUGÈRE, G. A criança e a cultura lúdica. In: KISHIMOTO, T. M. (Org.). 0 brincar e suas teorias. São Paulo: Pioneira Thomson Learning, 2002. p. 19-32.

DESLAURIERS, J. P.; KÉRISIT, M. O delineamento da pesquisa qualitativa. In: POUPART, J. et al. (Org.). A pesquisa qualitativa: enfoques epistemológicos e metodológicos. 2. ed. Petrópolis: Vozes, 2010. p. 127-153.

DIAS, C. R. A função do professor com crianças pequenas: impasses frente ao enigma do infantil no contexto escolar. 2014. 117 f. Dissertação (Mestrado em Psicologia) - Instituto de Psicologia da Universidade de São Paulo, São Paulo, 2014.

BRASIL. Constituição da República Federativa do Brasil. Brasília, DF: Senado Federal, 1988. Disponível em: http://www.planalto.gov.br/ccivil 03/decretolei/Del5452.htm. Acesso em 28/07/17.
BRASIL. Lei de Diretrizes e Bases da Educação Nacional. Lei no 9394/96. Disponível em http://portal.mec.gov.br/seesp/arquivos/pdf/lei9 394 Idbn1.pdf. Acesso em 20/03/17.

BRASIL. Ministério da Educação. Referencial curricular para educação infantil. Brasília, 1998.

BRASIL. Brinquedos e brincadeiras nas creches: manual de orientação pedagógica. Brasília: MEC/SEB, 2012.

BRASIL. Diretrizes curriculares Nacionais para Educação Infantil. Brasília: MEC/SEB, 2009.

CUNHA, M. I. O tema da formação de professores: trajetórias e tendências do campo na pesquisa e na ação. Educação e Pesquisa, São Paulo, v. 39, n. 3, p. 609-625, jul./set. 2013. Disponível em: http://www.scielo.br/pdf/ep/v39n3/aop1096.pdf . Acesso em: 03 fev. 2017.

FIGUEIRA, N. T. 0 parque como espaço educativo: práticas corporais num projeto de formação de professores para educação infantil. 2014. 177 f. Dissertação (Mestrado em Educação) - Faculdade de Educação da Universidade de São Paulo, São Paulo, 2014.

GATTI, B. ; BARRETTO, E. S. S. ; ANDRÉ, M. Políticas docentes no Brasil: um estado da arte. Brasília: UNESCO, 2011. Disponível em: http://unesdoc.unesco.org/images/0021/002121 /212183por.pdf. Acesso em: 05 fev. 2017.

KISHIMOTO, T. M. Avanços e retrocessos na formação dos profissionais de educação infantil. In: MACHADO, M. L. de. A. (Org.). Encontros e desencontros em educação infantil. São Paulo: Cortez, 2002. p. 107-115.

KRAMER, S. Pesquisando infância e educação: um encontro com Walter Benjamin. In: KRAMER, S; LEITE, M. I. (Orgs). Infância: fios e desafios da pesquisa. Campinas: Papirus, 1996. p. 13-38.

NÓVOA, Antônio (Org.). Profissão Professor. Portugal: Porto Ed., 1999.

OLIVEIRA, Z. R. Educação Infantil: fundamentos e métodos. São Paulo: Cortez, 2002. 
OLIVEIRA, Z. R. (org.). 0 trabalho do professor na Educação Infantil. São Paulo: Biruta, 2012.

OLIVEIRA, Z. R. Formação Continuada em Educação Infantil: a construção de uma agenda de possibilidades. In: GUIMARÂES, C. M; REIS, P. G. R. dos. (Org). Professores e Infâncias: estudos e experiências. Araraquara: Junqueira e Marin, 2011. p. 13-28.

PASQUALINI, S. T. O brincar e suas várias linguagens: um estudo de caso enfocando a formação do professor de educação infantil. 2004. 97 f. Dissertação (Mestrado em Educação e Cultura) - Universidade do Estado de Santa Catarina, Florianópolis, 2004.

SAVIANI, D. Formação de professores: aspectos históricos e teóricos do problema do contexto brasileiro. Revista Brasileira de Educação, Rio de Janeiro, v. 14, n. 40, jan./abr, p. 143-155, 2009.

PIAGET, J. O juízo moral na criança. Tradução Elzon Lenardon. São Paulo: Summus, 1994.

VYGOTSKY, L. S. Pensamento e Linguagem. São Paulo: Martins Fontes, 1995.

Recebido para publicação em: 02/10/2017

Revisado em: 06/11/2017

Aceito em: 13/12/2017 